\title{
Personality Impairment in Children and Adolescents with ADHD
}

\author{
Anna Helena Haddad ${ }^{1}$ \\ Latife Yazigi ${ }^{1}$ \\ Ana Cristina Resende ${ }^{2}$ \\ Kelsy Catherina Nema Areco ${ }^{1}$ \\ Norma Lottenberg Semer ${ }^{1}$ \\ Francisco Lotufo Neto ${ }^{3}$
}

\begin{abstract}
Attention deficit hyperactivity disorder in children and adolescents manifests itself in a heterogeneous manner as regards personality aspects. This study aimed to evaluate, by using the Ego Impairment Index, the personality functioning characteristics of children and adolescents between 9 and 15 years old (to be completed), diagnosed with the disorder (clinical group) and compare them with a non-clinical group. The groups included 42 participants each. The Kiddie Schedule for Affective Disorders and Schizophrenia for School-Age Children - Present and Lifetime version was used for diagnosis, and the Rorschach Performance Assessment System (R-PAS) was utilized for personality traits. When compared to their peers, the participants in the clinical group showed ability to discern adaptive behaviors through proper judgment, difficulty in keeping thinking and reasoning processes stable, a negative view of themselves and others, in addition to difficulty in establishing cooperative relationships.
\end{abstract}

Keywords: attention deficit disorder with hyperactivity, Rorschach test, children, adolescents, personality

\section{Comprometimento da Personalidade em Crianças e Adolescentes com TDAH}

Resumo: O transtorno da falta de atenção com hiperatividade em crianças e adolescentes manifesta-se de forma heterogênea com relação aos aspectos de personalidade. O presente estudo teve por objetivo avaliar, por meio do Índice de Enfraquecimento do Ego, características do funcionamento da personalidade de crianças e adolescentes, entre 9 e 15 anos incompletos, com o diagnóstico do transtorno (grupo clínico) e compará-las com um grupo não-clínico. Os grupos contemplaram 42 participantes cada. Utilizouse para o diagnóstico a entrevista Kiddie-Sads Referente ao Momento Presente e ao Longo da Vida, e o Sistema de Avaliação por Performance no Rorschach (R-PAS) para as características de personalidade. Os participantes do grupo clínico, quando comparados com seus pares, mostraram capacidade de discernir comportamentos adaptativos por meio de julgamento adequado, dificuldade em manter estáveis os processos de pensamento e raciocínio, visão negativa de si próprios e dos demais, dificuldade para estabelecer relacionamentos cooperativos.

Palavras-chave: transtorno da falta de atenção com hiperatividade, teste de Rorschach, crianças, adolescentes, personalidade

\section{Deterioro de la Personalidad en Niños y Adolescentes con TDAH}

Resumen: El trastorno por déficit de atención con hiperactividad es uno de los más encontrados entre las patologías infantiles y se manifiesta de forma no homogénea con relación a los aspectos de personalidad. Este estudio comparó a través de lo Índice de Enflaquecimiento del Ego características de personalidad de niños y adolescentes entre 9 y 15 años incompletos con diagnóstico con un grupo de mismo sexo y edad sin diagnóstico. Cada grupo estaba compuesto por 42 participantes. Se utilizó la entrevista Kiddie-Sads sobre el momento presente y al largo de la vida para el diagnóstico y el Sistema de Evaluación por Performance en el Rorschach (R-PAS), para las características de personalidad. El grupo clínico mostró capacidad para discernir conductas adaptativas a través del juicio adecuado, dificultad para mantener estables los procesos de pensamiento y razonamiento, visión negativa de sí mismos y de los demás, dificultad para establecer relaciones de cooperación.

Palabras clave: trastorno por déficit de atención con hiperactividad, test de Rorschach, niños, adolescentes, personalidad

${ }^{1}$ Universidade Federal de São Paulo, São Paulo-SP, Brazil

${ }^{2}$ Pontificia Universidade Católica de Goiás, Goiânia-GO, Brazil

${ }^{3}$ Universidade de São Paulo, São Paulo-SP, Brazil

Correspondence address: Anna Helena Haddad. Universidade Federal de São Paulo. Rua Borges Lagoa 1080, cj 1107, Vila Clementino, São PauloSP. 04038-003. E-mail: annahelenahaddad@hotmail.com
Attention Deficit Hyperactivity Disorder (ADHD) is considered a very common neurodevelopmental condition among childhood pathologies (Polanczyk, Salum, Sugaya, Caye, \& Rohde, 2015). According to the Diagnostic and Statistical Manual of Mental Disorders (DSM-5) by the American Psychiatric Association [APA] (2013), the diagnostic criteria for the disorder include a persistent pattern 
of inattention and/or hyperactivity/impulsivity that interfere with psychosocial behavior observed in different contexts, such as at home, at school and in social networks (AgnewBlais et al., 2018).

Inattention symptoms are manifested by: difficulty in focusing or sustaining attention; difficulty with instructions, rules and deadlines; forgetfulness in daily tasks and activities and disorganization. Hyperactivity/impulsivity symptoms involve excessive motor activity that is not appropriate for the moment; hasty, thoughtless actions with great potential for harm to the child, as well as the desire for immediate reward and the impossibility of postponing satisfaction and dealing with frustration (APA, 2013).

Studies by Hansen, Oerbeck, Skirbekk, Petrovski and Kristensen (2018) have shown higher ADHD prevalence in boys, who have a higher frequency of externalizing symptoms, such as aggressiveness and impulsivity. Because girls have a higher degree of internalizing symptoms, such as mood disorder and anxiety, they tend to be underdiagnosed for ADHD.

The disorder is commonly diagnosed in childhood, but contrarily to what was believed, in most cases, it is not resolved when children reach puberty. In this period, higher rates of risky behaviors are observed, such as: accidents; use of drugs, digital media and alcohol; school dropout; early motherhood and paternity (Weinstein, Yaacov, Manning, Danon, \& Weizman, 2015; Wüstner et al., 2019). Such behaviors are explained not only by a failure to perceive risk, but also by psychosocial factors (Longhini, Rios, Peron, \& Neufeld, 2017) that influence self-regulation, making adolescents more susceptible to experiencing frustration and anger outbursts.

The problems shown by adolescents with ADHD do not always differ from the behaviors exhibited by children; however, their context, complexity and potential to cause harm change considerably. Not infrequently, comorbidities with Oppositional Defiant Disorder (ODD), anxiety and depression emerge in this period, thus making ADHD occurrence more complex (Anastopoulos et al., 2018; Hansen et al., 2018). For example, impulse-control difficulties can lead to disruptive behaviors in the classroom, and social difficulties can result in higher anxiety levels (Vazquez, Sibley, \& Campez, 2018). It is also at this time that school problems become more evident (Sayal, Washbrook, \& Propper, 2015). For these reasons, experts have emphasized the need for an approach that includes diversity in the research field in order to cover neurobiological factors (Shaw \& Polanczyk, 2017), perinatal risk factors (Elgen, Sommerfelt, Leversen, \& Markestad, 2015), environmental factors (Wüstner et al., 2019) and personality characteristics (Gomez \& Corr, 2014).

This study is focused on the latter aspect, on the personality assessment of children and adolescents with ADHD, using, for this purpose, the third review of the Ego Impairment Index (EII-3) of the Rorschach Performance Assessment System (R-PAS) (Meyer, Viglione, Mihura, Erard, \& Erdberg, 2017). The index consists of a set of variables that assess aspects related to general personality impairment, such as: (a) unrealistic and conventional perception of facts that informs whether the individual is able to compose accurate impressions of himself and the environment, favoring a good adaptation through proper judgment (variable $F Q$-, or Formal Quality minus); (b) difficulties in thinking, complexity and degree of impairment of these difficulties, that is, from small slips of speech, loss of focus of the line of reasoning to a more severe degree of ideation and judgment impairment (variable WSumCog, or Weighted Sum of the Six Cognitive Codes); (c) verbalizations that subjects would normally inhibit in their personal interactions, including the formal assessment situation, which are related to dysphoric affections and/ or affective immaturity, negative and unfavorable attitudes towards bodily functions, the existence of collaboration in interpersonal relationships, sexuality, as well as aspects related to impulsivity and destructiveness (variable CritCont\% or Critical Contents); (d) problems in the sphere of thought and distancing from reality in ideational activity (variable $M$-); (e) understanding of oneself, people and relationships (Codes of Good Human Representation - GHR and Poor Human Representation - PHR); (f) productivity, task engagement and cognitive flexibility (variable $R$, or Total Number of Answers) (Meyer et al., 2017).

Despite Rorschach's great potential for understanding personality characteristics, there are few studies in the literature that have investigated ADHD using such test (Gomez \& Corr, 2014). Cotugno (1995) studied three groups of children aged 5 and 6 years (one group diagnosed with ADHD, another with different psychopathology complaints and a non-clinical group) using the Comprehensive System (Exner, 2003) and observed that the group with ADHD showed inefficient psychological resources to face daily life demands, especially in situations of stress (Lambda $\uparrow$ ), vulnerability to depressive experiences and hurtful affections (DEPI $\uparrow$ and $S u m S h \uparrow)$, avoidance of situations involving the expression of feelings ( $A f r \downarrow)$, self-centering $(3 r+(2) / R \uparrow)$, tendency to apprehend reality in an individualistic or distorted manner $(X-\% \uparrow, X u \% \uparrow)$, in addition to being more influenced by a negative view of oneself and of peers (CDI $\uparrow$ ).

Bartell and Solanto (1995) compared data shown by children between 5 and 11 years old diagnosed with ADHD and ADHD comorbid with ODD $(\mathrm{N}=24)$ to normative data by using the Comprehensive System (Exner, 2003). The authors concluded that children in clinical groups were less able to perceive themselves and others in a realistic way $(H \downarrow)$ and less able to think before acting when managing their problems and to be empathic with others $(M \downarrow)$. They tended to see reality in an individualistic or distorted fashion $(X-\% \uparrow)$, which made it difficult for these children to anticipate the consequences of their actions.

Meehan et al. (2008) evaluated children between 7 and 10 years old diagnosed with ADHD $(\mathrm{N}=28)$ by using the Comprehensive System (Exner, 2003). Children in the clinical group who did not meet all the criteria for ADHD proposed by DSM-5 composed the control group $(N=14)$. The group with ADHD showed difficulty in accessing internal 
coping resources to organize, process and represent their experiences $(E A \downarrow)$, less ability to think before acting when managing their problems and to be able to show empathy towards others $(M \downarrow)$. According to the authors, these limitations would facilitate emotional dysregulation, that is, impulsive behaviors would be a response to strong or unmodulated emotions.

More recently, Ando et al. (2019) investigated the personality characteristics of 31 children between 7 and 17 years old, diagnosed with ADHD in the absence of medication, by using R-PAS. A comparison was made with a normative group of children. The main findings refer to the difficulties in understanding oneself, people and relationships $(P H R \% \uparrow)(M=118.8 ; S D=16.1 ; p \leq$ $0.001)$, absence of human behavior mentalization $(H \downarrow)$ $(M=81.1 ; S D=13.3 ; p \leq 0.001)$, inability to develop and integrate experience or human activities $(M \downarrow)(M=89.1$; $S D=13.4 ; p \leq 0.001)$, difficulties in objectively perceiving reality $(F Q-\uparrow)(M=114.5 ; S D=19.08 ; p \leq 0.001)$ and general personality impairment, $(E I I-3 \uparrow)(M=114.6$; $S D=19,1 ; p \leq 0.001)$.

In general, the cited studies showed that children with ADHD had, among other characteristics, difficulties in objectively perceiving reality ( $F Q-\uparrow$ ) (Ando et al., 2019; Bartell \& Solanto, 1995; Cotugno, 1995), atypical or distorted understanding of interpersonal relationships (CDI $\uparrow$ ) (Cotugno, 1995), (PHR\% $\uparrow$ ) (Ando et al., 2019), in addition to general personality impairment (EII-3 $\uparrow$ ) (Ando et al., 2019). It is believed that such characteristics can be evaluated and better elucidated by the EII-3 and its set of variables. Therefore, the present study aimed to evaluate, by using the Ego Impairment Index, personality functioning characteristics of children and adolescents between 9 and 15 years old, diagnosed with ADHD (clinical group), and compare them with a non-clinical group.

\section{Method}

\section{Participants}

The total sample consisted of 84 children, of both sexes, aged between 9 and 15 years old (to be completed) $(M=11.4 ; S D=1.6)$. The clinical group $(N=42)$ was composed of 38 boys and 4 girls with a primary diagnosis of ADHD seen at a Specialist Outpatient Psychiatric Services for Children and Adolescents at a public teaching hospital in the city of São Paulo. The inclusion criteria adopted were: (a) primary ADHD diagnosis performed by a specialized physician at the outpatient clinic from which the patient came; (b) showing 6 or more symptoms of inattention and/or 6 or more symptoms of hyperactivity/impulsivity, according to the Schedule for Affective Disorders and Schizophrenia for School-Aged Children - Present and Lifetime Version (K-SADS-PL) (Kaufman et al., 1997), for at least 6 months, and having the symptoms started before 12 years of age; (c) being able to complete the Rorschach test. The exclusion criteria adopted were: (a) individuals with a clinical diagnosis of bipolar disorder (manic phase); (b) comorbidities with acute psychotic conditions or intellectual disability referred to in the medical records. In addition to these, 5 children did not enter the study because they did not meet the proposed criteria.

The follow-up time at the outpatient clinics ranged from 0 (newly arrived patients) to 10.8 years. Regarding the symptoms diagnosed by the K-SADS, 52\% showed a combination of symptoms (six or more) of inattention and hyperactivity/impulsivity; 31\% mainly showed symptoms of inattention (six or more), and 17\% mainly showed symptoms (six or more) of hyperactivity.

As for medication, 90\% were using some type of medication at the time of assessment, and $10 \%$ were not medicated. Regarding comorbidities, all participants met the criteria for at least one. ODD was the most prevalent comorbidity $(78.0 \%)$, followed by Generalized Anxiety Disorder (GAD) (45.0\%), Separation Anxiety (19.0\%), Conduct Disorder (29.0\%), phobia (19.0\%) and clinical comorbidities $(19 \%$, with common variable immunodeficiency, hypothyroidism, myopia, obesity, prematurity, weight loss due to stimulants and nystagmus), enuresis $(17.0 \%)$, encopresis $(10.0 \%)$, social phobia $(10.0 \%)$, depression (10.0\%), Obsessive Compulsive Disorder (OCD) (10.0\%), Post-traumatic Stress Disorder (PTSD) (10.0\%), vocal or motor tics $(7.0 \%)$, panic disorder $(5.0 \%)$, bipolar disorder $(5.0 \%)$, psychosis $(2.0 \%)$ and drug use $(2.0 \%)$.

The non-clinical group consisted of children and adolescents with typical development, enrolled in elementary schools, 33 of whom were males and 9 females. The inclusion criterion adopted was: (a) being enrolled in the age-appropriate grade at school; (b) showing evidence of typical development; (c) having at least average non-verbal intelligence as measured by the Raven's Colored Progressive Matrices Test - Special Scale (Angelini, Alves, Custódio, Duarte, \& Duarte, 1999), and Raven's Progressive Matrices General Scale (JC Raven, 2008). Typical development was inferred from information provided by the participant's guardians using a Participant Characterization Form. An eligible child was not included in the study for showing Autistic Spectrum Disorder (ASD).

\section{Instruments}

Schedule for Affective Disorders and Schizophrenia for School-Aged Children - Present and Lifetime Version, $K-S A D S-P L$ (Kaufman et al., 1997). A semi-structured interview based on DSM criteria, with the purpose of obtaining a symptom severity score and assessing a psychiatric disorder history at the present time and throughout life, in children and adolescents aged 6 to 18 years. An accuracy study among evaluators in Brazil (2003) found 99.7\% reliability in a screening interview and $98 \%$ inter-evaluator reliability in a diagnostic interview. Test-retest reliability, calculated by using the Kappa coefficient and considering 20 participants, with an interval from 1 (one) to 5 weeks, ranged between 0.74 and 0.90 , according to the current diagnostic categories 
and throughout life. For ADHD, the index was 0.63 at the present time, which is considered satisfactory. K-SADS was applied only to the clinical group.

Rorschach Performance Assessment System (R-PAS) (Meyer et al., 2017). Consisting of 10 cards (Rorschach ${ }^{\circledR}$ is a registered trademark of Hogrefe AG - Bern, Switzerland) with inkblots, the examinee is invited to say what they look like. The examinee is asked to provide two, perhaps three answers per card, and when offering only one, he/she is encouraged to provide more answers, with the card being carefully removed after the fourth answer. Reliability studies between evaluators in R-PAS showed intraclass correlation coefficients ranging between 0.78 and 1.00 , which are considered very good and excellent (Pignolo et al., 2017; Resende, Viglione, Yazigi, \& Martins, 2019).

Participant characterization form. Instrument answered by one of the child's or adolescent's guardians, designed to collect information concerning the children's sex, age, schooling and general health status.

Raven's Progressive Matrices - General Scale (J.C. Raven, 2008) and Raven's Colored Progressive Matrices TestSpecial Scale (Angelini, Alves, Custódio, Duarte, \& Duarte, 1999). Both aim to assess general nonverbal intelligence - the $\mathrm{g}$ factor, which is the ability to observe, think and check the level of intellectual development. They were used in order to exclude cases with suspected intellectual impairment (percentile $<25$ ). The Raven's test showed internal consistency measured by a Cronbach's Alpha of 0.87 and 0.8 for the Special and General Scales, respectively, showing high results indicating that the studied sample's response pattern was consistent (J. Raven, JC Raven, \& Court, 2019). All children and adolescents showed compatible results with the average or higher level of intelligence, ranging from the 25 th to the 99 th percentiles.

\section{Procedure}

Data collection. Children and adolescents, diagnosed with ADHD and longitudinally assisted by a team of health professionals from a public institution, were referred to the researcher on the day of their consultation appointment and evaluated by both instruments, K-SADS-PL and R-PAS, in a single encounter. Their guardians were informed about the objectives of the study and asked whether they could have additional time after the medical consultation to participate in it. Those who gave their consent signed an Informed Consent Form (ICF). Subsequently, the children/adolescents were also invited to give their consent.

All participants were in good health at the time of the assessment and had periodic (usually monthly) consultations with a psychiatrist. The consultation offices were large and airy and had a desk and a computer for application of the instruments. After a brief interview with the child/ adolescent, seeking to establish a good relationship, R-PAS was applied by the first researcher, while the companions waited in the waiting room. The application was conducted using the side-by-side position. The answers were directly typed onto a laptop computer, and the percepts' locations were manually noted on specific worksheets (Hogrefe CETEPP Publishers). All participants showed good availability for the test and were able to complete it. The K-SADS-PL questionnaire was subsequently applied by a psychiatrist or the researcher in charge, who was duly certified for that purpose. At this moment, the participants remained together with their companions. The questions were addressed to the children/ adolescents, and their companions were encouraged to share by contributing with clarifications or further information. The answers were recorded manually. Each instrument's application required from 40 minutes to 1 (one) hour.

As for the non-clinical group, in the case of public schools, authorization from the State and Municipal Education Secretariats was requested in order to conduct the study. Then, the schools' managers were contacted, and they also agreed to it. During the parents' meetings at the institution, the guardians were informed about the objectives of the investigation, and those who agreed to participate signed an ICF. The children/adolescents' assessment was performed during class hours, with teachers being responsible for determining the best time for the students to leave. They were firstly submitted to the collective application of the Raven's Test - Special Scale (applied to participants aged 9 to 11 years and 11 months old) or General (applied to participants aged 12 years old or over) in reserved rooms at the institutions themselves (large private rooms with officestyle desks and chairs). The duration of the procedure was approximately 30 minutes in groups comprising a maximum of 9 students. On another day, students were individually submitted to R-PAS during a meeting lasting approximately 1 (one) hour. Two psychologists with management certification by R-PAS were responsible for the applications. The test protocols were collected directly onto a laptop computer on specific spreadsheets.

Considering the R-PAS protocols (clinical and nonclinical groups), the first and third authors were responsible for coding them all. The codifications were reviewed by a team of psychologists from a public university. To establish accuracy between evaluators, $24 \%$ of the protocols in each group were randomly selected and coded by the second author, who was blinded to the original codes. The accuracy between evaluators was analyzed using the Intraclass Correlation Coefficient (ICC). The results indicated that the EII-3 and its individual variables showed precision between very good and excellent, ranging from 0.78 to 1.00 (Weir, 2005). The protocols showing codification divergences were rediscussed, thus resulting in more adequate coding, according to agreement between the evaluators. The protocols with their final codifications were entered on an international online platform (https://www.r-pas.org/) whose use is restricted to psychologists registered with their professional councils and which was developed for the quantitative correction of R-PAS and database compilation. In all test application environments, it was possible to ensure privacy and confidentiality of the information collected. 
Data analysis. Demographic and R-PAS variables were described and compared between the two groups referred to: the clinical (ADHD) and non-clinical groups. For the EII-3 and its set of variables, the values of the Standard Score $(M=100 ; S D=10)$ were used, as they are more easily comparable with those in recent studies using Rorschach (Ando et al., 2019), in addition to enabling comparisons considering the stage of development in which the child/ adolescent is and the characteristic difficulties of each stage. The reliability of the Raven's test was analyzed using Cronbach's Alpha. Categorical variables were described in terms of absolute $(N)$ and relative (\%) frequency, and numerical variables by measures of central tendency and variability, both shown in tables, for each of the groups. The Chi-Square statistical test $\left(X^{2}\right)$ was used for comparison of categorical variables between groups. The $t$-test was applied for numerical variables when they showed normal distribution; otherwise the Mann-Whitney test was utilized. In order to decide about and fit and the test used to compare numerical variables between groups, adherence to normal distribution was also tested by the Shapiro-Wilk test, and equality of variances by the Levene test. As a measure of effect size, Cohen's $d$ (comparisons made by the $t$-test) or the $U / m . n$ statistic (comparisons made by the Mann-Whitney test, where $m$ is the size of the case group and $n$ of the control group) was calculated. The values calculated for effect size were interpreted as follows: <0.19: Insignificant; 0.20 to 0.49: Small; 0.50 to 0.79: Medium; 0.80 to 1.29: Large; $>$ 1.30: Very Large (Hulley, Cummings, Browner, Grady, \& Newman, 2015). All data analysis was performed using the Statistical Package for Social Sciences (SPSS), version 20.0, with a significance level $(\alpha)$ of $5 \%$.

\section{Ethical Considerations}

The study followed all provisions of Resolution No. 466/12 by the National Health Council (CNS) and its supplements. The study was submitted to the Research Ethics Committee (CEP) of Universidade de São Paulo (Registration No. 513.519) and approved on January 5, 2014) (CAAE: 22667514.0.0000.0068).

\section{Results}

Table 1 shows the socio-demographic characteristics of the two groups under study (clinical and non-clinical). There was no statistically significant difference in the comparison of the groups regarding variables sex $(p=0.131)$, school type $(p=0.251)$, age $(p=0.931)$ or schooling $(p=0.168)$.

Table 1

Absolute and relative frequency of variables sex, school type, age, and schooling in the clinical and non-clinical groups

\begin{tabular}{|c|c|c|c|c|c|c|}
\hline & & \multicolumn{4}{|c|}{ Group } & \multirow{3}{*}{ Test } \\
\hline & & \multicolumn{2}{|c|}{ clinical } & \multicolumn{2}{|c|}{ non-clinical } & \\
\hline \multirow{4}{*}{ Sex } & & $N$ & $\%$ & $N$ & $\%$ & \\
\hline & Female & 4 & 9.5 & 9 & 21.4 & \multirow{3}{*}{$\begin{array}{c}\text { Chi-square } \\
\left(\mathrm{X}^{2}=2.275 ; \mathrm{gl}=1 ; p=0.131\right)\end{array}$} \\
\hline & Male & 38 & 90.5 & 33 & 78.6 & \\
\hline & Total & 42 & 100.0 & 42 & 100.0 & \\
\hline \multirow{4}{*}{$\begin{array}{l}\text { School } \\
\text { type }\end{array}$} & & $N$ & $\%$ & $N$ & $\%$ & \multirow{4}{*}{$\begin{array}{c}\text { Chi-square } \\
\left(\mathrm{X}^{2}=1.317 ; g l=1 ; p=0.251\right)\end{array}$} \\
\hline & Private & 17 & 40.5 & 12 & 28.6 & \\
\hline & Public & 25 & 59.5 & 30 & 71.4 & \\
\hline & Total & 42 & 100.0 & 42 & 100.0 & \\
\hline \multirow{6}{*}{ Age } & $M$ & 11.4 & & 11.4 & & \multirow{6}{*}{$\begin{array}{c}\text { Mann-Whitney } \\
(\mathrm{U}=872.5 ; p=0.931)\end{array}$} \\
\hline & Median & 11.5 & & 11.0 & & \\
\hline & $S D$ & 1.6 & & 1.6 & & \\
\hline & Minimum & 9 & & 9 & & \\
\hline & Maximum & 14 & & 14 & & \\
\hline & $N$ & 42 & & 42 & & \\
\hline \multirow{6}{*}{ Schooling } & $M$ & 5.9 & & 6.5 & & \multirow{6}{*}{$\begin{array}{c}\text { Mann-Whitney } \\
(\mathrm{U}=712.0 ; p=0.168)\end{array}$} \\
\hline & Median & 6.0 & & 6.5 & & \\
\hline & $S D$ & 1.8 & & 1.7 & & \\
\hline & Minimum & 2 & & 3 & & \\
\hline & Maximum & 9 & & 9 & & \\
\hline & $N$ & 41 & & 42 & & \\
\hline
\end{tabular}


Table 2 shows the descriptive statistics of the EII-3 and its set of variables as well as the comparison of the groups in relation to such variables. When comparing the groups, the EII-3 and two of the variables in its set showed significantly higher values with a Large effect size: $E I I-3$ $(M=110.52 ; S D=18.86 ; p<0.001 ; d=1.130)$, (1) The Weighted Sum of the Six Cognitive Codes or WSumCog $(M=110.31 ; S D=19.08 ; p<0.001 ; d=1.095),(2)$ Codes of Poor Human Representation or PHR\% $(M=111,22$; $S D=18.46 ; p<0.001 ; d=0.860)$. The other variables in the index did not show statistically significant differences when comparing the groups: (3) Formal quality minus or $F Q$ - answers $(M=112.45 ; S D=17.19 ; p=0.004$; $d=0.655)$, (4) Critical Content or CritCont $(M=94.02$; $S D=15.30 ; p=0.097) ;(5) M-(M=100.43 ; S D=11.49$; $p=0.735) ;(6) R(M=99.57 ; S D=16.86 ; p=0.196)$.

Table 2

Comparison of the clinical and non-clinical groups'performances in relation to the EII-3 and the set of its variables

\begin{tabular}{|c|c|c|c|c|c|c|c|c|c|c|}
\hline Variable & Group & $N$ & $M$ & Median & $S D$ & Min & Max & Test value & $p$ & Cohen's D \\
\hline \multirow[t]{2}{*}{ EII-3 } & clinical & 42 & 110.52 & 114.5 & 18.86 & 73 & 143 & $(t=5.177 ; g l=82)$ & $<0.001$ & 1.130 \\
\hline & non-clinical & 42 & 90.93 & 91 & 15.68 & 64 & 120 & & & \\
\hline \multirow[t]{2}{*}{ FQ- } & clinical & 42 & 112.45 & 108 & 17.19 & 78 & 143 & $(t=3.001 ; g l=76.3)$ & 0.004 & 0.655 \\
\hline & non-clinical & 42 & 102.48 & 101 & 12.98 & 78 & 132 & $*$ & & \\
\hline \multirow[t]{2}{*}{ WSumCog } & clinical & 42 & 110.31 & 112 & 19.08 & 79 & 148 & $(t=5.016 ; g l=71.4)$ & $<0.001$ & 1.095 \\
\hline & non-clinical & 42 & 92.57 & 92 & 12.70 & 79 & 125 & $*$ & & \\
\hline \multirow[t]{2}{*}{ CritCont $\%$} & clinical & 42 & 94.02 & 93.5 & 15.30 & 70 & 123 & $(t=1.681 ; g l=82)$ & 0.097 & \\
\hline & non-clinical & 42 & 88.86 & 89 & 12.76 & 70 & 111 & $* *$ & & \\
\hline \multirow[t]{2}{*}{ M- } & clinical & 42 & 100.43 & 95 & 11.49 & 95 & 143 & $(\mathrm{U}=855.5)$ & 0.735 & \\
\hline & non-clinical & 42 & 99.14 & 95 & 8.91 & 95 & 123 & & & \\
\hline \multirow[t]{2}{*}{ PHR\% } & clinical & 37 & 111.22 & 111 & 18.46 & 75 & 136 & $(t=3.752 ; g l=74)$ & $<0.001$ & 0.860 \\
\hline & non-clinical & 39 & 96.28 & 100 & 16.22 & 75 & 136 & & & \\
\hline \multirow[t]{2}{*}{$\mathrm{R}$} & clinical & 42 & 99.57 & 99 & 16.86 & 60 & 146 & $(t=1.308 ; g l=62.5)$ & 0.196 & \\
\hline & non-clinical & 42 & 95.71 & 92 & 8.98 & 88 & 122 & $*$ & & \\
\hline
\end{tabular}

Note. ${ }^{*}$ Test-t (parametric) fitted for unequal variances; **Mann-Whitney Test (non-parametric).

\section{Discussion}

The present study aimed to evaluate personality characteristics of children and adolescents between 9 and 15 years old diagnosed with ADHD by using the R-PAS EII3 index in order to compare them with a non-clinical group. The differences found in the EII-3 were towards an increase in values in the clinical group. The data corroborate the reports by Ando et al. (2019), who compared children with ADHD to a normative group and found significantly higher results in the EII-3, which suggests difficulties in the overall personality functioning in their sample.

The literature (Ando et al., 2019; Bartell \& Solanto, 1995; Cotugno, 1995) found prevalence of reality apprehension in a subjective and distorted manner $(F Q-\uparrow)$ in groups with ADHD, with a predominance of subjective value judgment over critical judgment of reality. In the present study, the children and adolescents evaluated were able to understand the consequences of their actions, similarly to the majority of the population, as well as to discern the most adaptive behaviors through appropriate judgment. The results were similar to those found by Ando et al. (2019), given that variable $F Q$ - showed to be in the upper mean range in the clinical groups in both studies.
Contrarily to the literature (Ando et al., 2019), statistically significant differences were found between the groups (clinical and non-clinical) in the Weighted Sum of the Six Cognitive Codes (WSum $\operatorname{Cog} \uparrow$ ). Children and adolescents in our clinical group most often showed mild cognitive distortions, such as the use of incorrect or invented words (Deviant Verbalizations or $D V$ ), possibly due to inattention or lack in formal education, as for example: "Benjamin", "navy green" and "inkblot" were used to refer to the perceptions of a "hummingbird", "navy blue" and "blotted ink", respectively. They also showed slightly more serious cognitive deviations through answers that violated the consideration of reality (Incongruous Verbalizations or $I N C$ ), such as: "I see a man with a tail and two bird heads" (INC) and "a trunk with heeled shoes" (INC). In addition, they showed answers that deviated from the task objectives, possibly due to difficulties in maintaining, stabilizing and controlling attention (Deviant Responses or $D R$ ), as in the example: "this looks like a leaf, very close to the fish, it even seems that it (the fish) is holding the leaf, there are people who are afraid of spiders and see spiders." $(D R)$. Some children/adolescents in the clinical group also showed impaired perceptual processes through the establishment of implausible and unreal relationships 
between facts (Fabulized Combination or FAB1), as in the perceptions: "a banana with two boys on top of it" and "two seahorses kissing a diamond", "a skeleton with fire eyes", or in perceptions characterized by the presence of blending images and flaws in the discrimination of figures: a "borboprosa" (Contamination or CON), that is, "borboleta" and "mariposa". The Fabulized Combination, the Incongruous Combination and the Contamination seem to constitute the way that the children in the clinical group found to be able to organize their perceptual field. The other studies (Bartell \& Solanto, 1995; Cotugno, 1995; Meehan et al., 2008) did not work with this variable.

The perception of fragmented figures ( $P H R-p r p \uparrow)$ prevailed for the children in the clinical group, such as "a foot", "a head", "the thing for peeing", idealized figures, "fairies", "supermen", "Pokémon", vulnerable figures, "a mangy dog", "a broken dinosaur", "a smashed butterfly", "a bleeding frog", scary figures, monsters, malevolent figures and vampires, showing that they are more influenced by a negative view of themselves and of their peers, in addition to showing greater difficulties in establishing cooperative relationships (Ando et al., 2019; Cotugno, 1995). According to Vazquez et al. (2018), difficulties in socializing can result in higher anxiety levels, which in turn, would be likely to intensify impulsive and affectively nonmodulated responses (Meehan et al., 2008).

Children and adolescents from both groups, clinical and non-clinical, showed good ability to censor or inhibit traumatic images (Critcont\%), as well as good task involvement $(R)$ during R-PAS application (Ando et al., 2019). The slightly higher mean of responses in the clinical group when compared to the non-clinical was possibly due to lower motor control, which makes these children more active and responsive to Rorschach.

Finally, children and adolescents from both groups showed good task engagement during R-PAS application. They seemed to be able to understand the consequences of their actions as is the majority of the population, as well as to discern the most adaptive behaviors through proper judgment. Mild cognitive distortions prevailed in the clinical group, possibly due to inattention or even to failures in formal education. Responses that deviated from the task objectives were also observed, resulting from difficulties in maintaining, stabilizing and controlling attention. The affective aspect, related to interest in exercising behavior control and willingness to do so, was also insufficient, given the prevalence of the "here and now" resulting from the difficulty in postponing satisfaction and dealing with frustration as well as from the impossibility of containing angry reactions. Would their uneasiness be disguising anxieties and would mood outbursts be disguising fears? For that, it would be of great interest to investigate the Stress and Distress domain, using the $E I I-3$ in future studies.

Thus, the study of children and adolescents' personalities using the EII-3 points out the psychological flaws that accompany difficulties in other fields, such as in the neurological, psychopedagogical and speechtherapy, resulting in the need for diversified care. Family involvement in treatment facilitates the development of mutual understanding of more successful relationships. The development of social skills and self-control favors the construction of pleasurable experiences which, in turn, facilitate the creation of groups of friends that can help the capacity to have insights concerning hostile and less adapted behaviors leading to isolation and alienation from peers. The establishment of a pedagogical guideline which meets the particularities of each child/adolescent has been shown to be important, as well as the encouragement and practice of sports and artistic activities that help to develop creativity and logical thinking.

The large number of distinct comorbidities found in the clinical group shows that ADHD is a multifaceted disorder, involving not only the symptoms of inattention, hyperactivity and impulsivity, but a series of other behavioral conditions that pose risk to development, such as anxiety, aggression, emotional dysregulation and psychotic symptoms, among others. It is suggested that these differences can be considered separately in a later study. A clinical control group, for example, a group with ADHD without any comorbidities, could help to discriminate differences between groups.

\section{Referências}

Agnew-Blais, J. C., Polanczyk, G. V., Danese, A., Wertz, J., Moffitt, T. E., \& Arseneault, L. (2018). Young adult mental health and functional outcomes among individuals with remitted, persistent and late-onset ADHD. The British Journal of Psychiatry, 213(3), 526-534. doi:10.1192/bjp.2018.97

American Psychiatric Association. (2013). Diagnostic and statistical manual of mental disorders: DSM-5 (5th ed.). Washington, DC: Author.

Anastopoulos, A. D., Du Paul, G. J., Weyandt, L. L., MorrisseyKane, E., Sommer, J. L., Rhoads, L. H., ... Gudmundsdottir, B. G. (2018). Rates and patterns of comorbidity among first-year college students with ADHD. Journal of Clinical Child and Adolescent Psychology, 47(2), 236-247. doi:10.1080/15374416.2015.1105137

Ando, A., Pignolo, C., Viglione, D. J., Zennaro, A., Cristofanelli, S., \& Ferro, L. (2019). Assessing the personality profile with ADHD characteristics using the Rorschach Performance Assessment System (R-PAS). Journal of Child and Family Studies, 28(5), 1196-1206. doi:10.1007/s10826-019-01359-y

Angelini, A. L., Alves, I. C. B., Custódio, E. M., Duarte, W. F., \& Duarte, J. L. M. (1999). Matrizes progressivas coloridas de Raven: Escala especial [Manual for Raven's Progressive Matrices and Vocabulary Scale. Section 2: The Couloured Progressive Matrices]. São Paulo, SP: CETEPP. 
Bartell, S. S., \& Solanto, M. V. (1995). Usefulness of the Rorschach inkblot test in assessment of attention deficit hyperactivity disorder. Perceptual and Motor Skills, 80(2), 531-541. doi:10.2466/pms.1995.80.2.531

Brasil, H. H. A. (2003). Desenvolvimento da versão brasileira da K-SADS-PL (Schudule for Affective Disorders and Schizophrenia for Scholl Aged Children Present and Lifetime Version) e estudo de suas propriedades psicométricas [Development of the Brazilian version of K-SADS-PL (Schedule for Affective Disorders and Schizophrenia for School Aged Children. Present and Lifetime Version) and study of psychometric properties] (Unpublished doctoral dissertation). Universidade Federal de São Paulo, São Paulo, SP.

Cotugno, A. J. (1995). Personality attributes of attention deficit hyperactivity disorder (ADHD) using the Rorschach inkblot test. Journal of Clinical Psychology, 51(4),554-562.doi:10.1002/1097-4679(199507)51:4<554: AID-JCLP2270510415>3.0.CO;2-Y

Elgen, S. K., Sommerfelt, K., Leversen, K. T., \& Markestad, T. (2015). Minor neurodevelopmental impairments are associated with increased occurrence of ADHD symptoms in children born extremely preterm. European Child \& Adolescent Psychiatry, 24(4), 463-470. doi:10.1007/s00787-014-0597-9

Exner, J. E. (2003). The Rorschach: A comprehensive system. Vol. 1: Basic foundations and principles of interpretation (4th ed.). Hoboken, NJ: Wiley.

Gomez, R., \& Corr, P. J. (2014). ADHD and personality: A meta-analytic review. Clinical Psychology Review, 34(5), 376-388. doi:10.1016/j.cpr.2014.05.002

Hansen, B. H., Oerbeck, B., Skirbekk, B., Petrovski, B. E., \& Kristensen, H. (2018). Neurodevelopmental disorders: Prevalence and comorbidity in children referred to mental health services. Nordic Journal of Psychiatry, 72(4), 285-291.doi:10.1080/08039488.2018.1444087

Hulley, S. B., Cummings, S. R., Browner, W. S., Grady, D. G., \& Newman, T. B. (2015). Delineando a pesquisa clínica [Designing clinical research] (M. S. Duncan \& A. G. Islabão, Trans., 4th ed.) Porto Alegre, RS: Artmed.

Kaufman, J., Birmaher, B., Brent, D., Rao, U., Flynn, C., Moreci, P., ... Ryan, N. (1997). Schedule for Affective Disorders and Schizophrenia for School-Age ChildrenPresent and Lifetime version (K-SADS-PL): Initial reliability and validity data. Journal of the American Academy of Child \& Adolescent Psychiatry, 36(7), 980-988.doi:10.1097/00004583-199707000-00021

Longhini, L. Z., Rios, B. F., Peron, S., \& Neufeld, C. B. (2017). Caracterização das habilidades sociais de adolescentes em contexto escolar [Characterization of social skills of teenagers in a school context]. Revista Brasileira de Terapias Cognitivas, 13(2), 131-137. doi:10.5935/1808-5687.20170018
Meehan, K. B., Ueng-McHale, J. Y., Reynoso, J. S., Harris, B. H., Wolfson, V. M., Gomes, H., \& Tuber, S. B. (2008). Selfregulation and internal resources in school-aged children with ADHD symptomatology: An investigation using the Rorschach inkblot method. Bulletin of the Menninger Clinic, 72(4), 259-282. doi:10.1521/bumc.2008.72.4.259

Meyer, G. J., Viglione, D. J., Mihura, J. L., Erard, E. E., \& Erdberg, P. (2017). Rorschach Sistema de Avaliação por Desempenho: Manual de aplicação, codificação e interpretação e manual técnico [Rorschach Performance Assessment System: Administration, coding, interpretation, and technical manual] (D. R. Silva \& F. K. Miguel, Trans.). São Paulo, SP: Hogrefe.

Pignolo, C., Giromini, L., Ando, A., Ghirardello, D., Di Girolamo, M., Ales, F., \& Zennaro, A. (2017). An interrater reliability study of Rorschach Performance Assessment System (R-PAS) raw and complexityadjusted scores. Journal of Personality Assessment, 99(6), 619-625. doi:10.1080/00223891.2017.1296844

Polanczyk, G. V., Salum, G. A., Sugaya, L. S., Caye, A., \& Rohde, L. A. (2015). Annual research review: A metaanalysis of the worldwide prevalence of mental disorders in children and adolescents. Journal of Child Psychology and Psychiatry, 56(3), 345-365. doi:10.1111/jcpp.12381

Raven, J., Raven, J. C., \& Court, J. H. (2019). CPM Raven: Matrizes Progressivas Coloridas de Raven: Manual técnico [CPM Raven's coloured progressive matrices: Technical manual] (J. J. Paula, C. G. M. F. Schlottfeldt, L. F. M. Diniz, \& G. A. A. Mizuta, Trans.). São Paulo, SP: Pearson.

Raven, J. C. (2008). Teste das matrizes progressivas: Escala geral Séries A,B,C,D e E [Raven's Progressive Matrices: Sets A,B,C,D,E] (F. Campos Trans.) Manual. Rio de Janeiro, RJ: Centro Editor de Psicologia Aplicada.

Resende, A. C., Viglione, D. J., Martins, L. D., \& Yazigi, L. (2019). Criterion validity of the Rorschach Developmental Index with children. Journal of Personality Assessment, 101(2), 191-198. doi:10.1080/00223891.2017.1368021

Sayal, K., Washbrook, E., \& Propper, C. (2015). Childhood behavior problems and academic outcomes in adolescence: Longitudinal population-based study. Journal of the American Academy of Child \& Adolescent Psychiatry, 54(5), 360-368.e2. doi:10.1016/j.jaac.2015.02.007

Shaw, P., \& Polanczyk, G. V. (2017). Combining epidemiological and neurobiological perspectives to characterize the lifetime trajectories of ADHD. European Child \& Adolescent Psychiatry, 26(2), 139-141. doi:10.1007/s00787-017-0944-8

Vazquez, A. L., Sibley, M. H., \& Campez, M. (2018). Measuring impairment when diagnosing adolescent ADHD: Differentiating problems due to ADHD versus other sources. Psychiatry Research, 264, 407-411. doi:10.1016/j.psychres.2018.03.083 
Weinstein, A., Yaacov, Y., Manning, M., Danon, P., \& Weizman, A. (2015). Internet addiction and attention deficit hyperactivity disorder among schoolchildren. The Israel Medical Association Journal: IMAJ, 17(12), 731-734. Retrieved from https://www.ima.org.il/FilesUploadPublic/ IMAJ/0/181/90631.pdf

Weir, J. P. (2005). Quantifying test-retest reliability using the intraclass correlation coefficient and the SEM. Journal of Strength and Conditioning Research, 19(1), 231-240. doi:10.1519/15184.1

Wüstner, A., Otto, C., Schlack, R., Hölling, H., Klasen, F., \& Ravens-Sieberer, U. (2019). Risk and protective factors for the development of ADHD symptoms in children and adolescents: Results of the longitudinal BELLA study. PloS One, 14(3), e214412. doi:10.1371/journal.pone.0214412

Anna Helena Haddad is a candidate to the Master's Program at Universidade Federal de São Paulo, São Paulo-SP, Brazil.

Latife Yazigi is a Professor at Universidade Federal de São Paulo, São Paulo-SP, Brazil.

Ana Cristina Resende is a Professor at Pontifícia Universidade Católica de Goiás, Goiânia-Go, Brazil.

Kelsy Catherina Nema Areco has an M.Sc. degree from Universidade Federal de São Paulo, São Paulo-SP, Brazil.

Norma Lottenberg Semer is a Professor at Universidade Federal de São Paulo, São Paulo-SP, Brazil.

Francisco Lotufo Neto is a Professor at Universidade de São Paulo, São Paulo-SP, Brazil.

\section{Authors' Contribution:}

All authors have made substantial contributions to this study's conception and design, to data analysis and interpretation and to the revision and approval of the manuscript's final version. All authors assume public responsibility for the manuscript's content.

Associate editor:

Luciana Mourão Cerqueira e Silva
Received: Jun. 24, 2019

1st Revision: Apr. 08, 2020

2nd Revision: Jun. 26, 2020

3rd Revision: Aug. 06, 2020

4th Revision: Aug. 17, 2020

Approved: Sep. 03, 2020

How to cite this article:

Haddad,A. H. et al. (2021). Personality impairment in children and adolescents with ADHD. Paidéia (Ribeirão Preto), 31, e3105.doi:https://doi.org/10.1590/1982-4327e3105 